\title{
How can evolutionary Medicine inform future personalized medicine?
}

Henneberg, M ; Saniotis, A

DOI: https://doi.org/10.2217/PME.11.99

Posted at the Zurich Open Repository and Archive, University of Zurich

ZORA URL: https://doi.org/10.5167/uzh-75192

Journal Article

Published Version

Originally published at:

Henneberg, M; Saniotis, A (2012). How can evolutionary Medicine inform future personalized medicine? Pharmacogenomics and Personalized Medicine, 9(2):171-173.

DOI: https://doi.org/10.2217/PME.11.99 


\section{How can evolutionary medicine inform future personalized medicine?}

\author{
"We can no longer count on 'nature' to balance conditions of human bodies, nor \\ can we assume that there is some fixed, immutable 'normal human' ideal that will \\ be automatically maintained through time."
}

\section{KEYWORDS: degenerative disease $\approx$ genetic load $\approx$ immunological uniqueness - individual variation $=$ reproduction}

\section{Evolutionary medicine is based on individual variation}

Evolutionary medicine is based on the Darwinian principle that individual variation is sorted in the process of its transmission from generation-to-generation by the forces of evolution. These are directional: mutations and natural selection; and nondirectional: gene flow, inbreeding, genetic drift and assortative mating [1]. Evolutionary medicine is relevant for personalized medicine since it can foster understanding into the relationship between disease and human populations. Evolutionary medicine can also offer nonproximate reasons as to why the body is susceptible to disease. Such awareness may assist towards implementing novel and personalized medical treatments.

The essence of the Darwinian principle is that each individual is different from other individuals and only individuals exist in reality while groupings of individuals into categories are products of the human mind that may be more or less useful for specific practical purposes [2]. In terms of evolutionary medicine it means that it is inappropriate to apply the same diagnostic methods and treatments to all people. Medical attention must be individualized. In its rudimentary form this principle is observed in routine medical practice when blood groups are used and specific genetic disorders can be recognized (hemoglobinopathies such as sickle cell anemia, thalassemia and metabolic problems such as phenylketonuria). However, with the advent of gene sequencing and proteomics, the individualization of treatments and diagnostic methods will expand in the future. Specific treatments can be designed for individual patients to provide maximum therapeutic results for their genetic and epigenetic makeup.

\section{Mutations are inevitable, they must be treated}

With the chemical instability of the DNA molecule it is inevitable that mutations occur. In the past, when the opportunity for natural selection was significant [3], many deleterious mutations were removed from the gene pool nearly as fast as they arose. At present, and looking to the future, in the situation of very significantly relaxed selection $[4,5]$, mutations will be accumulating in the human gene pool. Numerous mutations will increase in proportion to the growing size of the human population [6]. This increase in the number and kinds of mutations presents a significant challenge to the future of medical practice. Eugenics, which aims at 'purification' of human genetic material has been thoroughly discredited during the 20th century. Thus, the only ethically acceptable approach in the future will be that of accepting the results of mutations as new forms of human physiology, immunology and anatomy, and their case-specific treatment. Since mutations are random changes in the genetic material, their most probable effect on the integrity of a human body is detrimental [7]. This poses a challenge for future personalized medicine because new variants of genetic material will have to be recognized and their, mostly detrimental, effects neutralized by case-specific treatments.

\section{Immunological uniqueness of individuals}

Our immune systems react to stimuli experienced during the early stages of our ontogeny. Infants and children encounter various environmental challenges and their immune systems 'learn' how to respond to them. In our highly urbanized environments the suite of

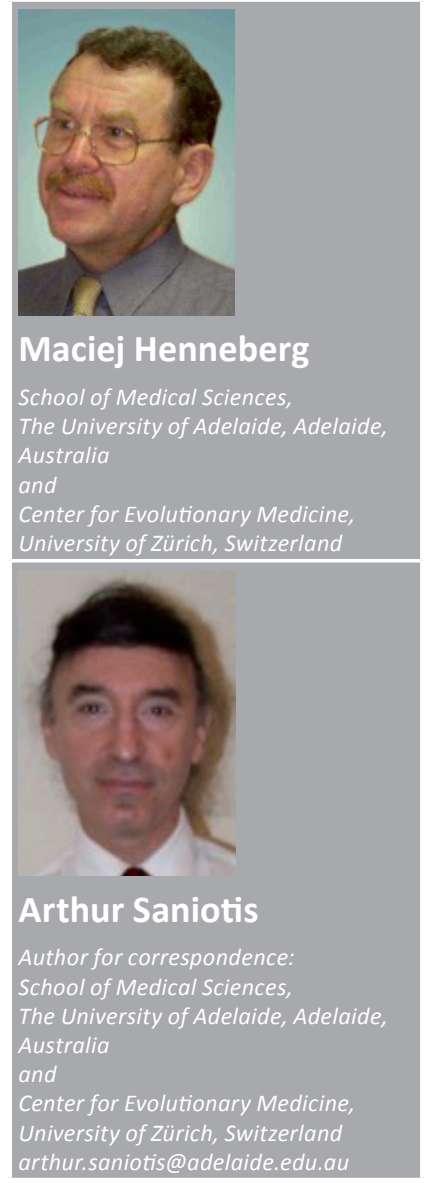

Future
Medicine $\mathrm{fS}$ 
antigens that the body of a child encounters is rapidly changing, with many traditional stimuli, such as internal and external parasites, removed by hygienic measures and a host of new chemicals introduced by industrial processes [8]. Moreover, increased travel exposes individuals to a greater number of immune challenges than in traditional sedentary societies. Each human being has a different history of exposure to stimuli, and thus, a somewhat unique immune system. Although our immune systems are evolving from generation-to-generation, they contain a large amount of adaptations to 'traditional' environments and during individual lives our adaptability to new immune challenges is limited. This produces allergies and hyperimmune responses to stimuli that an individual encounters during their life, especially when changing places of residence and working environments. Since individuals are variable in their responses to immune system stimuli, treatment of particular patients will require a personalized approach.

"...only individuals exist in reality while groupings of individuals into categories are products of the human mind that may be more or less useful for specific practical purposes."

\section{Degenerative diseases}

With increased longevity 'degenerative' diseases have become the primary cause of death, overtaking infectious diseases [9]. Prominent among them are those of the circulatory system, osteoarthritis and diseases of the CNS. Neoplasms are another serious problem. At present, severe cases of circulatory diseases, neoplasms and of osteoarthritis are treated surgically through blood vessel enlargements/replacements, tumor removal, joint implants and mechanical stabilization (spinal fusion). Loss of neurons in the CNS will probably be treated in the future through the use of stem cells. Improvement of brain function and of the special sense organs will be achieved by brain-machine interactions [10]. In the rudimentary form, such machine enhancements of special sense organs are already available (cochlear implants) or are in advanced stages of research (ocular implants). Moreover, current research in brain-machine interfaces is in the area of motor control [11] and interfacing the nervous system parenchyma [10]. Each individual has a different life history, and thus, a different suite of degenerative problems.
Chemical therapies of degenerative diseases are only partially successful. They await future improvements in terms of individualization of delivery of chemicals to coordinate their impact with that of the patient's own immune system and of the precise targeting of anatomical locations through the use of nanotechnology for drug delivery [12]. In both cases, treatments will have to be personalized taking into account individual immune rhythms and anatomical variations in patient's bodies.

\section{Individual reproductive needs}

With the relaxation of natural selection, and modernization of living conditions, infertility has become a problem. Females often yield to pressures of their careers and postpone having children until late in their lives. Birth control, which in the 20th century was mostly aimed at prevention of unwanted pregnancies and births, now gained a sizeable 'positive' element - compensation of infertility where techniques are applied to enhance ability to get pregnant and give birth. It is the right of every human being to have progeny. Thus, assistance in reproductive success has become an important part of medicine. Having children, especially going through the complex experience of pregnancy and motherhood, is one of the most intimate human endeavors. Each patient may be different not only in the biological characteristics determining reproductive success or problems, but also in psychological approach to parenthood. Thus, assisted reproductive treatments will also have to be personalized.

"...treatments will have to be personalized taking into account individual immune rhythms and anatomical variations in patient's bodies."

\section{Concern for the future}

Helping a patient with a particular ailment may perpetuate this ailment in future generations. Help should still be provided but in a manner that will not have future consequences. We can no longer count on 'nature' to balance conditions of human bodies, nor can we assume that there is some fixed, immutable 'normal human' ideal that will be automatically maintained through time. In reality, only individual patients exist and modes of their existence will define the entire human condition in the future. This is precisely where evolutionary medicine can prove to be beneficial in offering a much needed heuristic for developing a complementary approach to future personalized medicine. 


\section{Financial \& competing interests disclosure}

The authors have no relevant affiliations or financial involvement with any organization or entity with a financial interest in or financial conflict with the subject matter or materials discussed in the manuscript. This includes employment, consultancies, honoraria, stock ownership or options, expert testimony, grants or patents received or pending, or royalties.

No writing assistance was utilized in the production of this manuscript.

\section{References}

1 Wright S. Classification of the factors of evolution. Cold Spring Harbor Symp. Quant. Biol. 20, 16-24 (1955).

2 Henneberg M. Two interpretations of human evolution: essentialism and Darwinism. Anthropological Rev. 72, 66-80 (2009).
3 Henneberg M. Reproductive possibilities and estimations of the biological dynamics of earlier human populations. J. Hum. Evol. 5, 41-48 (1976).

4 Stephan C, Henneberg M. Medicine may be reducing the human capacity to survive. Med. Hypotheses 57, 633-637 (2001).

5 Saniotis A, Henneberg M. Medicine could be constructing human bodies in the future. Med. Hypotheses 77(4), 560-564 (2011).

6 Hawks J, Wang ET, Cochran GM, Harpending HC, Moyzis RK. Recent acceleration of human adaptive evolution. Proc. Natl Acad. Sci. USA 104(52), 20753-20758 (2007).

7 Brace CL. The probable mutation effect. American Naturalist 98, 453-455 (1964).

8 Weinstock JV, Summers R, Elliott DE. Helminths and harmony. Gut 53(1), 7-9 (2004).
9 Omran AR. The epidemiologic transition theory: a preliminary update. J. Trop. Pediatr. 29, 305-316 (1983).

10 Rodolfo L, Makarov VA. Brain-machine interface via a neurovascular approach. In: Converging Technologies for Improving Human Performance: Nanotechnology, Biotechnology, Information Technology and Cognitive Science. Roco MC, Bainbridge WS (Eds). Kluwer Academic Press, Dordrecht, The Netherlands, 244-251 (2003).

11 Friehs GM, Vasilios A, Zerris CL, Ojakangas M, Fellows R, Donoghue JP. Brain-machine and brain-computer interfaces. Stroke 35, 2702-2705 (2004).

12 Coventry BJ, Ashdown ML, Quinn MA, Markovic SN, Yatomi-Clarke SL, Robinson AP. CRP identifies homeostatic immune oscillations in cancer patients: a potential treatment targeting tool? J. Transl. Med. 30(7), 102 (2009). 